\title{
AIP
}

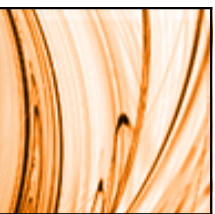

\section{Light-current characteristic of a quantum well laser with asymmetric barrier layers}

Levon V. Asryan, Natalia V. Kryzhanovskaya, Mikhail V. Maximov, Fedor I. Zubov, and Alexey E. Zhukov

Citation: Journal of Applied Physics 114, 143103 (2013); doi: 10.1063/1.4824545

View online: http://dx.doi.org/10.1063/1.4824545

View Table of Contents: http://scitation.aip.org/content/aip/journal/jap/114/14?ver=pdfcov

Published by the AIP Publishing

\section{Articles you may be interested in}

Improvement of the performance characteristics of deep violet InGaN multi-quantum-well laser diodes using step-graded electron blocking layers and a delta barrier

J. Appl. Phys. 113, 123108 (2013); 10.1063/1.4798388

Light-current characteristics of quantum dots with localized recombination

Appl. Phys. Lett. 87, 083109 (2005); 10.1063/1.2034091

Intrinsic nonlinearity of the light-current characteristic of semiconductor lasers with a quantum-confined active region

Appl. Phys. Lett. 81, 2154 (2002); 10.1063/1.1508171

Effects of $p$-doping and nonradiative processes on the current-voltage characteristics of long wavelength quantum-well laser diodes

J. Appl. Phys. 84, 4087 (1998); 10.1063/1.368694

Current-voltage characteristics of long wavelength quantum-well laser diodes

J. Appl. Phys. 83, 1183 (1998); 10.1063/1.366903

MIT LINCOLN

LABORATORY CAREERS

Discover the satisfaction of innovation and service

to the nation
- Space Control

- Air \& Missile Defense

- Communications Systems \& Cyber Security

- Intelligence, Surveillance and

Reconnaissance Systems

- Advanced
Electronics
- Tactical Systems
- Homeland
Protection
- Air Traffic Control

LINCOLN LABORATORY

MASSACHUSETTS INSTITUTE OF TECHNOLOGY

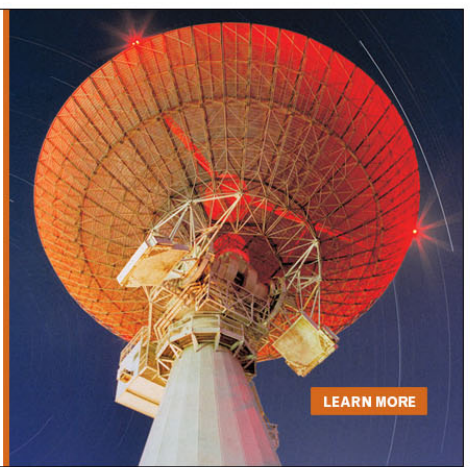




\title{
Light-current characteristic of a quantum well laser with asymmetric barrier layers
}

\author{
Levon V. Asryan, ${ }^{1, a)}$ Natalia V. Kryzhanovskaya, ${ }^{2, b)}$ Mikhail V. Maximov, ${ }^{3, c)}$ \\ Fedor I. Zubov, ${ }^{2, d)}$ and Alexey E. Zhukov ${ }^{2, e)}$ \\ ${ }^{1}$ Virginia Polytechnic Institute and State University, Blacksburg, Virginia 24061, USA \\ ${ }^{2}$ St. Petersburg Academic University, St. Petersburg 194021, Russia \\ ${ }^{3}$ Ioffe Physico-Technical Institute, St. Petersburg 194021, Russia
}

(Received 8 July 2013; accepted 23 September 2013; published online 10 October 2013)

\begin{abstract}
Light-current characteristic (LCC) of a novel type of quantum well (QW) lasers-QW lasers with asymmetric barrier layers (ABLs) - is studied. The ABLs (one on each side of the QW) prevent electrons from entering the hole-injecting side of the structure and holes from entering the electron-injecting side. The use of ABLs thus suppresses the parasitic electron-hole recombination outside the QW and eliminates the mechanism of sublinearity of the LCC in conventional lasers associated with this recombination and with the carrier capture delay into the QW. As a result, no matter how slow is the carrier capture into the QW, the LCC of an ABL QW laser is virtually linear. In an ABL laser containing indent layers between the QW and each of the ABLs (parasitic recombination still occurs in these thin layers), even in the case of slow capture of carriers into the QW, the LCC is also considerably more linear than in a reference conventional QW laser. (C) 2013 AIP Publishing LLC. [http://dx.doi.org/10.1063/1.4824545]
\end{abstract}

\section{INTRODUCTION}

In the conventional design of injection lasers, there is always bipolar (i.e., both electron and hole) population, and hence electron-hole recombination, not only in the active region [quantum wells (QWs), quantum wires, or quantum dots (QDs)] but also in the optical confinement layer (OCL) ${ }^{1-10}$ Parasitic recombination outside the active region presents a major cause for the temperature-dependence of the threshold current in conventional semiconductor lasers. It also leads to sublinearity of the light-current characteristic (LCC) in such lasers. ${ }^{11,12}$

In Refs. 13 and 14, to suppress bipolar population and hence electron-hole recombination outside QDs, tunnelinginjection of both electrons and holes into QDs from two separate QWs (one on each side of the QD layer) was proposed. In Refs. 14 and 15, an alternative, band-engineering, approach was proposed to suppress parasitic recombination outside QDs. The approach was based on the use of two asymmetric barrier layers (ABLs) - one on each side of the QD layer. The ABL in the electron-injecting side of the structure should ideally prevent holes from entering that side while not hindering the electron-injection into QDs. The $\mathrm{ABL}$ in the hole-injecting side should prevent electrons from entering that side while not hindering the hole-injection into QDs. The use of stopper layers was discussed earlier in Ref. 16 to improve the carrier confinement in the active region and the optical confinement in the waveguide. In Ref. 17, a

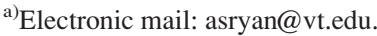

b)Electronic mail: kryj@mail.ioffe.ru.

${ }^{c)}$ Electronic mail: maximov@beam.ioffe.ru.

d)Electronic mail: fedyazu@mail.ru.

${ }^{\mathrm{e})}$ Electronic mail: zhukale@gmail.com.
}

QW laser with a hole stopper (in the form of a six-period superlattice) emitting at $3.15 \mu \mathrm{m}$ was discussed.

In Ref. 18, the concept of ABLs was applied to a singleQW laser. Realistic material systems for ABL QW lasers were identified. A lower and less temperature-sensitive threshold current was predicted in Ref. 18 for ABL QW lasers as compared to conventional quantum well (CQW) lasers. In Ref. 19, an ABL QW laser was fabricated and operated at room temperature for the first time; it demonstrated a considerably higher temperature-stability of the threshold current (the characteristic temperature $T_{0}=143 \mathrm{~K}$ ) as compared to the reference CQW laser $\left(T_{0}=99 \mathrm{~K}\right)$.

Our previous work was focused on the effect of ABLs on threshold characteristics of QW lasers. In this paper, we study the LCC (the output optical power as a function of the pump current) of ABL QW lasers. We show that in an ABL QW laser the parasitic electron-hole recombination outside the QW is totally suppressed and the LCC is virtually linear. We also show that in an ABL QW laser with indent layers, which is easier to fabricate, the LCC is considerably more linear as compared to the reference CQW laser.

\section{THEORETICAL MODEL}

The output optical power of a diode laser is given by

$$
P(j)=\frac{\hbar \omega}{e} S\left(j-j_{\text {th }}\right) \eta_{\text {int }}(j) \frac{\beta}{\beta+\alpha_{\text {int }}},
$$

where $\hbar \omega$ is the photon energy, $e$ is the electron charge, $S=L W$ is the cross-section of the junction, $L$ is the cavity length, $W$ is the lateral size of the device, $j$ is the injection current density, $j_{\text {th }}$ is the threshold current density, $\beta$ is the 
mirror loss, and $\alpha_{\text {int }}$ is the internal optical loss. In what follows, we neglect $\alpha_{\text {int }}$ as compared to $\beta$.

In Eq. (1), $\eta_{\text {int }}$ is the internal differential quantum efficiency defined as ${ }^{20}$

$$
\eta_{\mathrm{int}}=\frac{j_{\mathrm{stim}}}{j-j_{\mathrm{th}}}
$$

where $j_{\text {stim }}$ is the current density of stimulated recombination in the active region of the laser.

In Refs. 11 and 12, a general approach to the internal quantum efficiency of semiconductor lasers with a quantumconfined active region was developed. The following expression for $\eta_{\text {int }}$ was derived, which applies to $\mathrm{QW}$, quantum wire, and QD lasers:

$$
\eta_{\text {int }}(j)=\frac{1}{\frac{1}{2}+\frac{j_{\text {th }}^{\mathrm{OCL}}}{j_{\text {capt } \text { th }}}+\sqrt{\left(\frac{1}{2}+\frac{j_{\text {th }}^{\mathrm{OCL}}}{j_{\text {capt th }}}\right)^{2}+\frac{j_{\text {th }}^{\mathrm{OCL}}}{j_{\text {capt } \text { th }}} \frac{j-j_{\text {th }}}{j_{\text {capt }, \text { th }}}}},
$$

where

$$
j_{\mathrm{th}}^{\mathrm{OCL}}=e b B_{3 \mathrm{D}}\left(n_{\mathrm{th}}^{\mathrm{OCL}}\right)^{2}
$$

is the threshold current density component associated with parasitic recombination outside the active region (i.e., in the OCL) and $j_{\text {capt, th }}$ is the current density of carrier capture from the OCL into the quantum-confined active region at the lasing threshold. In Eq. (4), $b$ is the OCL thickness, $B_{3 \mathrm{D}}$ is the three-dimensional (3D) radiative recombination constant for the OCL material, and $n_{\mathrm{th}}^{\mathrm{OCL}}$ is the free carrier density in the OCL at the lasing threshold.

As seen from Eq. (3), $\eta_{\text {int }}$ decreases with increasing $j$ and, consequently, the dependence of $P$ on $j$ (the LCC) is sublinear- see Eq. (1).

In the case of QW lasers,

$$
j_{\mathrm{th}}=j_{\mathrm{th}}^{\mathrm{QW}}+j_{\mathrm{th}}^{\mathrm{OCL}} \text {, }
$$

where

$$
j_{\mathrm{th}}^{\mathrm{QW}}=e B_{2 \mathrm{D}}\left(n_{\mathrm{th}}^{\mathrm{QW}}\right)^{2}
$$

is the threshold current density component associated with spontaneous radiative recombination in the $\mathrm{QW}, B_{2 \mathrm{D}}$ is the two-dimensional (2D) radiative recombination constant for the QW material, and $n_{\mathrm{th}}^{\mathrm{QW}}$ is the $2 \mathrm{D}$-carrier density in the QW at the lasing threshold.

The $2 \mathrm{D}$-carrier density $n^{\mathrm{QW}}$ in the $\mathrm{QW}$ is related to the occupancy $f_{\mathrm{n}}$ of the lower edge of the quantum-confinement subband in the QW as follows: ${ }^{21}$

$$
n^{\mathrm{QW}}=N_{\mathrm{c}}^{2 \mathrm{D}} \ln \frac{1}{1-f_{\mathrm{n}}},
$$

where $N_{\mathrm{c}}^{2 \mathrm{D}}$ is the $2 \mathrm{D}$ effective density of states in the QW.
If charge neutrality holds in the QW, the occupancy of the subband edge in the QW is found from the following lasing condition:

$$
g^{\max }\left[f_{\mathrm{n}}-\left(1-f_{\mathrm{n}}\right)^{\frac{1}{M}}\right]=\beta
$$

where $g^{\max }$ is the maximum modal gain of the laser (see Refs. 10 and 18 for $g^{\max }$ ) and $M=m_{\mathrm{hh}}^{\mathrm{QW}} / m_{\mathrm{e}}^{\mathrm{QW}}$ is the ratio of the heavy-hole effective mass to the electron effective mass in the QW.

The solution of Eq. (8), $f_{\mathrm{n}}$, is pinned, i.e., does not depend on the pump current density $j$. Correspondingly, the 2D-carrier density $n^{\mathrm{QW}}$ in the $\mathrm{QW}$ [see Eq. (7)] is pinned at its threshold value $n_{\mathrm{th}}^{\mathrm{QW}}$. Hence, the current density $j^{\mathrm{QW}}=e B_{2 \mathrm{D}}\left(n^{\mathrm{QW}}\right)^{2}$ of spontaneous recombination in the $\mathrm{QW}$ does not change with $j$ above the lasing threshold and is given by Eq. (6).

In contrast to $n^{\mathrm{QW}}$ and $j^{\mathrm{QW}}$, the free-carrier density $n^{\mathrm{OCL}}$ and the current density $j^{\mathrm{OCL}}$ of spontaneous recombination in the OCL increase with $j$ above the lasing threshold,

$$
j^{\mathrm{OCL}}=e b B_{3 \mathrm{D}}\left[n^{\mathrm{OCL}}(j)\right]^{2} .
$$

The increase of $n^{\mathrm{OCL}}$ with $j$ is due to noninstantaneous capture of carriers from the OCL into the quantum-confined active region, ${ }^{11,12}$

$$
n^{\mathrm{OCL}}(j)=n_{\mathrm{th}}^{\mathrm{OCL}}\left[1+\frac{j-j_{\mathrm{th}}}{j_{\text {capt }, \text { th }}} \eta_{\text {int }}(j)\right],
$$

where $\eta_{\text {int }}(j)$ is given by Eq. (3).

Using Eq. (78) of Ref. 12 and Eq. 12 of Ref. 22, we can express the free-carrier density in the OCL at the lasing threshold in terms of the 2D-carrier density in the QW as follows:

$$
n_{\mathrm{th}}^{\mathrm{OCL}}=n_{1} \frac{n^{\mathrm{QW}}}{N_{\mathrm{c}}^{2 \mathrm{D}}}+\frac{1}{\mathrm{v}_{\text {capt }, 0}\left(1-f_{\mathrm{n}}\right)} B_{2 \mathrm{D}}\left(n^{\mathrm{QW}}\right)^{2} \text {, }
$$

where $n_{1}=N_{\mathrm{c}}^{3 \mathrm{D}} \exp \left(-E_{\mathrm{n}} / T\right), N_{\mathrm{c}}^{3 \mathrm{D}}$ is the $3 \mathrm{D}$ effective density of states in the OCL, $E_{\mathrm{n}}$ is the carrier excitation energy from the QW to the OCL, $T$ is the temperature (in units of energy), and $\mathrm{v}_{\text {capt, } 0}$ is the velocity (in units of $\mathrm{cm} / \mathrm{s}$ ) of carrier capture into an unoccupied QW.

The current density of carrier capture into the QW at the lasing threshold is

$$
j_{\text {capt }, \text { th }}=e \mathrm{v}_{\text {capt }, 0}\left(1-f_{\mathrm{n}}\right) n_{\mathrm{th}}^{\mathrm{OCL}} \text {. }
$$

The capture velocity $\mathrm{v}_{\text {capt, } 0}$ is the key (and actually the only) parameter adequately describing the carrier capture from a $3 \mathrm{D}$ bulk region (OCL) into a $2 \mathrm{D}$ region $(\mathrm{QW})-$ see Refs. 11, 12, and 22-27. As seen from Eqs. (10) and (12), the higher $\mathrm{v}_{\text {capt, } 0}$, the slower is the increase of $n^{\mathrm{OCL}}$ and $j^{\mathrm{OCL}}$ with increasing $j$. In the limiting case of $\mathrm{v}_{\text {capt, } 0} \rightarrow \infty$ (instantaneous capture into the $\mathrm{QW}), n^{\mathrm{OCL}}$ and $j^{\mathrm{OCL}}$ will remain pinned at their threshold values $n_{\mathrm{th}}^{\mathrm{OCL}}$ and $j_{\text {th }}^{\mathrm{OCL}}$.

With Eqs. (4) and (12), the expression (3) for $\eta_{\text {int }}$ becomes 


$$
\eta_{\mathrm{int}}=\frac{1}{\frac{1}{2}+\frac{b B_{3 \mathrm{D}} n_{\mathrm{th}}^{\mathrm{OCL}}}{\mathrm{v}_{\mathrm{capt}, 0}\left(1-f_{\mathrm{n}}\right)}+\sqrt{\left[\frac{1}{2}+\frac{b B_{3 \mathrm{D}} n_{\mathrm{th}}^{\mathrm{OCL}}}{\mathrm{v}_{\mathrm{capt}, 0}\left(1-f_{\mathrm{n}}\right)}\right]^{2}+\frac{b B_{3 \mathrm{D}}}{e\left[\mathrm{v}_{\mathrm{capt}, 0}\left(1-f_{\mathrm{n}}\right)\right]^{2}}\left(j-j_{\mathrm{th}}\right)}} .
$$

As seen from Eq. (13), the smaller is the thickness $b$ of the region (outside the QW) wherein bipolar carrier population exists and hence parasitic electron-hole recombination occurs, the higher is $\eta_{\text {int }}$ and the weaker is its decrease with $j$. In the case of CQW lasers [Fig. 1(a)], $b=b_{\mathrm{OCL}}$ is the thickness of the entire OCL; hence, the internal efficiency drops considerably with $j$ (Figs. 2 and 4, solid curves) and the LCC is sublinear (Figs. 3 and 5, solid curves).

In contrast to $\mathrm{CQW}$ lasers, in an $\mathrm{ABL} \mathrm{QW}$ laser of Fig. 1(b), there is no region of bipolar carrier population, i.e., no parasitic electron-hole recombination outside the QW-we should set $b=0$ in Eq. (13). Thus, no matter how slow is the carrier capture into the QW, there will be $100 \%$ quantum efficiency (Figs. 2 and 4, horizontal dotted lines),

$$
\eta_{\text {int }}=1
$$
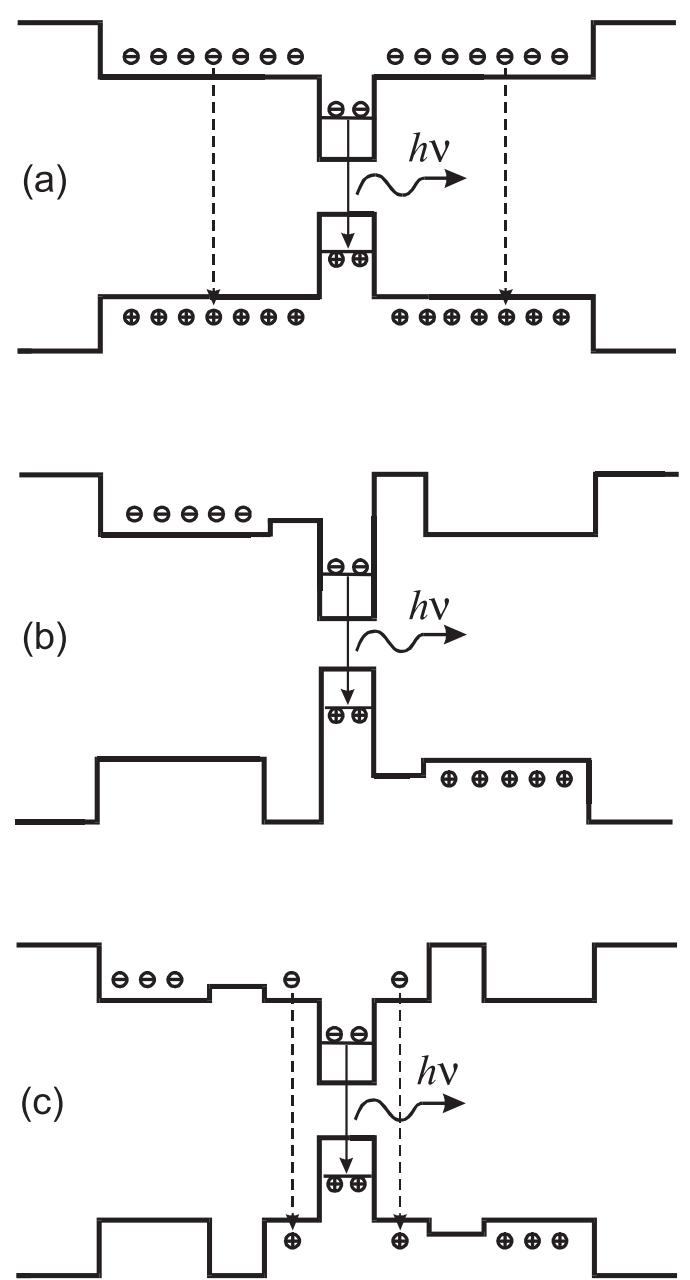

FIG. 1. Energy band diagrams of CQW laser (a) and ABL QW laser without (b) and with indent layers (c). The vertical solid arrows show the electronhole recombination in the QW. The vertical dashed arrows show the parasitic electron-hole recombination outside the QW. and, correspondingly, a linear LCC (Figs. 3 and 5, dotted lines),

$$
P(j)=\frac{\hbar \omega}{e} S\left(j-j_{\mathrm{th}}\right) .
$$

In an $\mathrm{ABL} \mathrm{QW}$ laser containing indent layers between the QW and each of the ABLs [Fig. 1(c)], the region of bipolar population outside the $\mathrm{QW}$, wherein the parasitic electron-hole recombination occurs, is restricted to these two thin indent layers only. Denoting by $b_{\text {ind }}$ the thickness of each indent layer, we should use

$$
b=2 b_{\text {ind }}
$$

in Eq. (13) to calculate $\eta_{\text {int }}$. Since $2 b_{\text {ind }}$ is much smaller than $b_{\mathrm{OCL}}(10 \mathrm{~nm}$ as compared to $0.4 \mu \mathrm{m}$ for the specific structures considered here), there will be only a slight decrease of $\eta_{\text {int }}$ with $j$ (Figs. 2 and 4, dashed-dotted curves) and only a slight sublinearity of the LCC (Figs. 3 and 5, dashed-dotted curves).

\section{DISCUSSION}

To apply our theoretical model, we consider a reference CQW laser [Fig. 1(a)] and ABL QW lasers without [Fig. 1(b)]

(a)
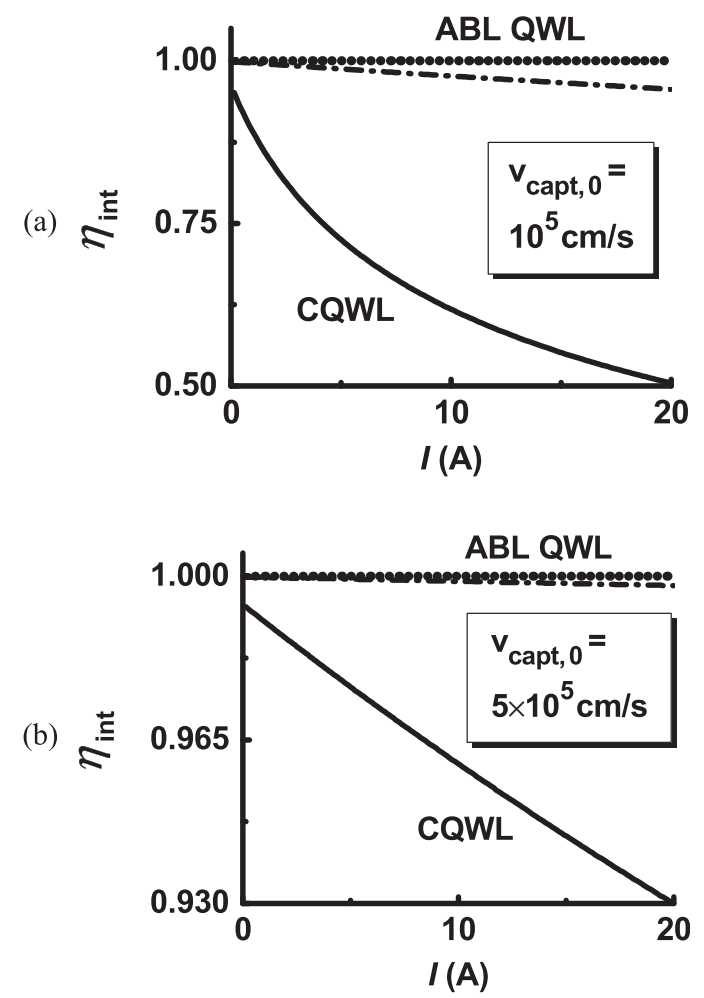

FIG. 2. Internal differential quantum efficiency in wide-lateral-size $(W=100 \mu \mathrm{m})$ long-cavity $(L=2 \mathrm{~mm})$ high-power structures vs. injection current. In Figs. 2-7, the solid, dotted, and dashed-dotted curves are for the CQW laser and ABL QW lasers without and with indent layers, respectively. 
(a)

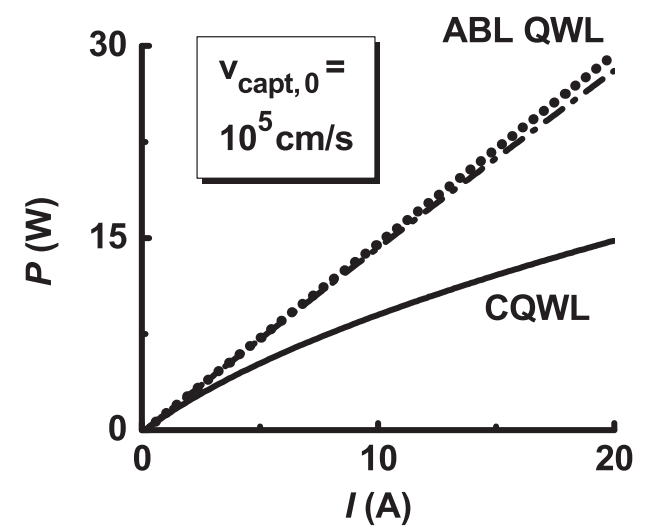

(b)

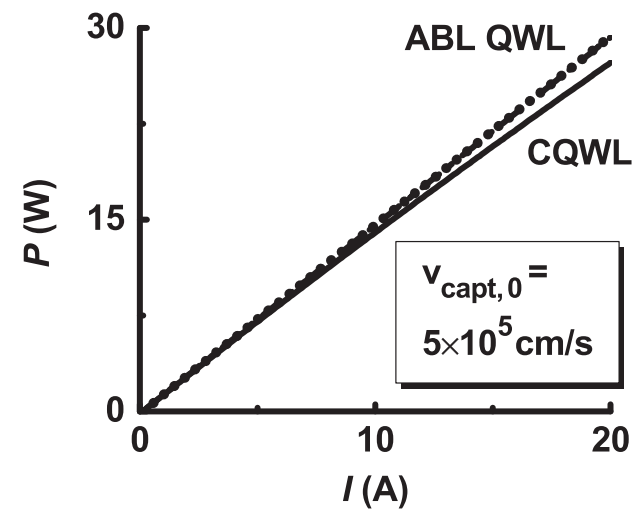

FIG. 3. Light-current characteristic in high-power structures.

and with indent layers [Fig. 1(c)]. For all the three structures, the material of the QW is GaAs and the material of the OCL is $\mathrm{Al}_{0.2} \mathrm{Ga}_{0.8}$ As. ${ }^{18}$ The OCL thickness $b_{\mathrm{OCL}}=0.4 \mu \mathrm{m}$ and the QW width is $75 \AA$. The lasing wavelength $\lambda_{0}=0.84 \mu \mathrm{m}$.

(a)
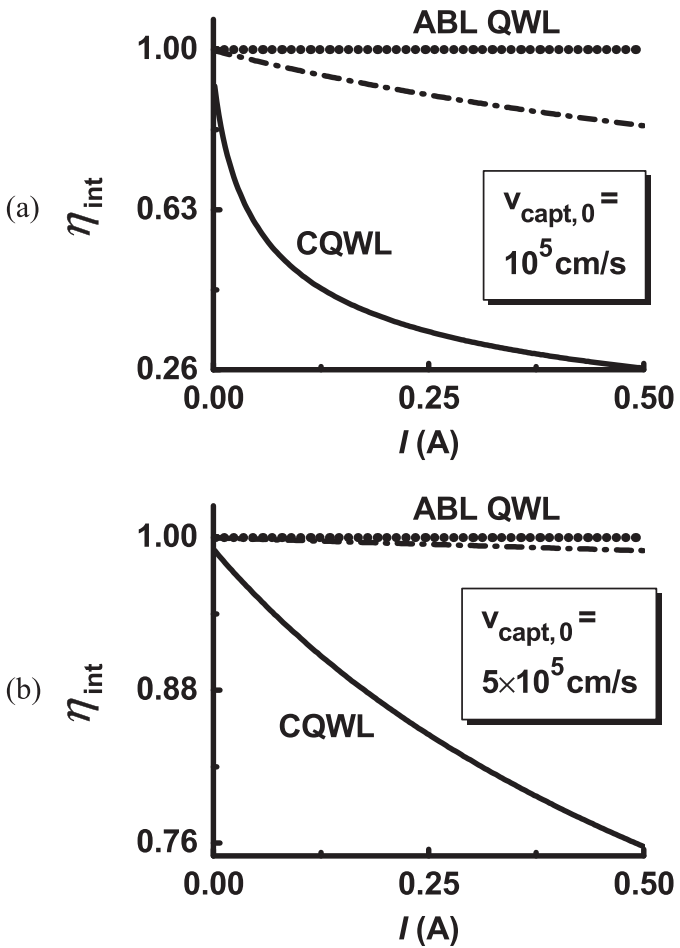

FIG. 4. Internal differential quantum efficiency in narrow-ridge ( $W=3 \mu \mathrm{m})$ short-cavity $(L=0.5 \mathrm{~mm})$ structures vs. injection current. (a)
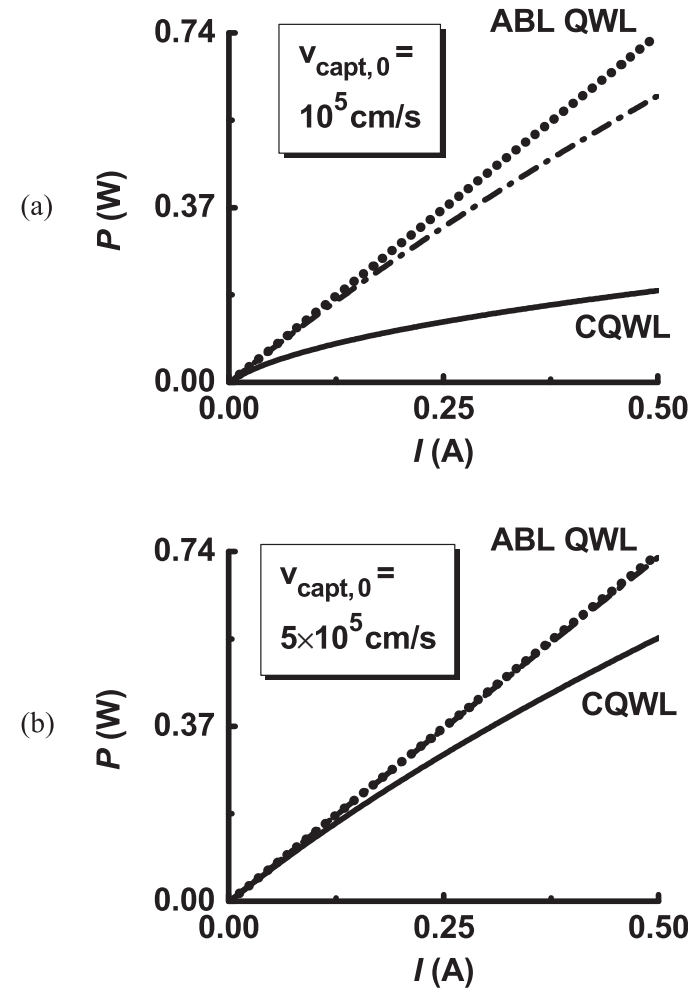

FIG. 5. Light-current characteristic in narrow-ridge short-cavity structures.

For both ABL lasers [without and with indent layerssee Figs. 1(b) and 1(c)], we assume that the ABLs function ideally, i.e., the left-(right-) hand-side ABL totally blocks holes (electrons) from entering the left-(right-) hand-side of the OCL while not hindering at all the electron-(hole-) injection into the QW. This assumption is justified as a first step to understand the potential of ABL QW lasers for high internal efficiency, which is the task of this work. The inclusion of tunneling of carriers through the ABLs and over-the-barrier escape of carriers is a topic of a separate rigorous study, which is one of our future tasks.

As was shown in Ref. 18, $\mathrm{Ga}_{0.87} \mathrm{In}_{0.13} \mathrm{As}_{0.51} \mathrm{P}_{0.49}$ and $\mathrm{Al}_{0.4} \mathrm{Ga}_{0.41} \mathrm{In}_{0.19}$ As can serve as candidate materials for the hole- and electron-blocking ABLs, respectively - there is a significant asymmetry in the conduction and valence band offsets at the heteroboundary between each of these materials and the material of the OCL $\left(\mathrm{Al}_{0.2} \mathrm{Ga}_{0.8} \mathrm{As}\right)$.

The material of the indent layers in the ABL laser with such layers [Fig. 1(c)] is the same as the material of the OCL and the thickness of each indent layer $b_{\text {ind }}=5 \mathrm{~nm}$. The reason for considering here an $\mathrm{ABL}$ laser with indent layers is that such a structure can be technologically easier to grow as compared to an $\mathrm{ABL}$ laser without such layers. $^{18}$

For each type of the lasers, we consider two structures(i) a wide-lateral-size $(W=100 \mu \mathrm{m})$ long-cavity $(L=2 \mathrm{~mm})$ high-power structure pumped by the current $I=L W j$ up to $20 \mathrm{~A}$ (which corresponds to the pump current density $\left.10 \mathrm{kA} / \mathrm{cm}^{2}\right)$ and (ii) a narrow-ridge $(W=3 \mu \mathrm{m})$ short-cavity $(L=0.5 \mathrm{~mm})$ structure pumped by the current up to $0.5 \mathrm{~A}$ (which corresponds to the pump current density $33 \mathrm{kA} / \mathrm{cm}^{2}$ ). The facet reflectivities are $R_{1}=1$ and $R_{2}=0.32$. Hence, the 
mirror loss $\beta=(1 / L) \ln \left(1 / \sqrt{R_{1} R_{2}}\right)$ is 2.85 and $11.4 \mathrm{~cm}^{-1}$ in high-power and narrow-ridge structures, respectively.

For each structure, we consider the cases of very slow capture of carriers into the QW $\left(\mathrm{v}_{\text {capt, },}=10^{5} \mathrm{~cm} / \mathrm{s}\right)$ and moderately slow capture $\left(\mathrm{v}_{\text {capt, } 0}=5 \times 10^{5} \mathrm{~cm} / \mathrm{s}\right)$. Both these values are within the reported range for $\mathrm{v}_{\text {capt, } 0} \cdot{ }^{23,25-27}$

As already discussed above, $\eta_{\text {int }}$ in an ABL QW laser without indent layers is unity (Figs. 2 and 4 ) and the LCC is linear (Figs. 3 and 5) no matter how slow is the carrier capture into the QW.

As seen from Figs. 2(a) and 4(a), in the case of very slow capture, the internal quantum efficiency of the CQW laser drops considerably with increasing $j$ in both the highpower and narrow-ridge structures and, consequently, the LCC is strongly sublinear [Figs. 3(a) and 5(a)]. In the ABL QW laser containing indent layers [Fig. 1(c)], the decrease of $\eta_{\text {int }}$ with $j$ is not large [Figs. 2(a) and 4(a)] and the deviation of the LCC from linearity is also not large [Figs. 3(a) and 5(a)].

As seen from Figs. 2(b) and 3(b), in the case of moderately slow capture in high-power structures, there is practically no difference between the two ABL lasers and only little difference between the ABL and CQW lasers. In the case of narrow-ridge structures, the difference between the two ABL lasers is also negligible [Figs. 4(b) and 5(b)], while the difference between the ABL and CQW lasers is noticeable $-\eta_{\text {int }}$ decreases by almost $25 \%$ [Fig. 4(b)] and the LCC is essentially sublinear in the CQW laser [Fig. 5(b)]. Hence, even if the carrier capture into the QW is not very slow in narrow-ridge short-cavity devices, the use of the ABL design instead of the conventional design will considerably improve the laser characteristics.

(a)

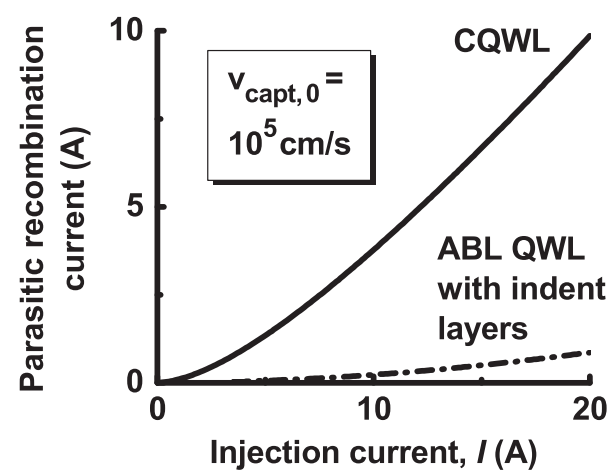

(b)

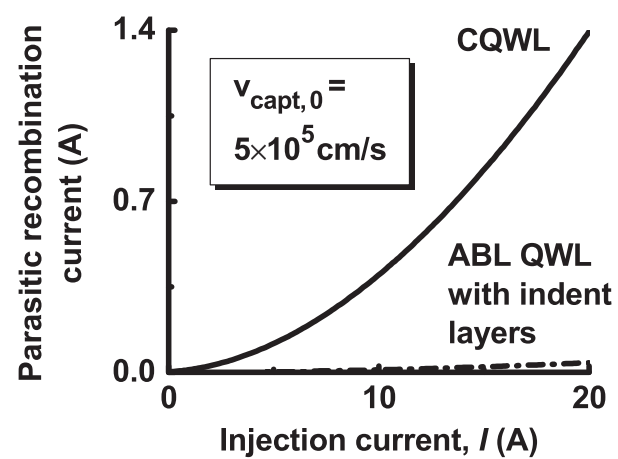

FIG. 6. Parasitic recombination current outside the QW in high-power structures vs. injection current. (a)

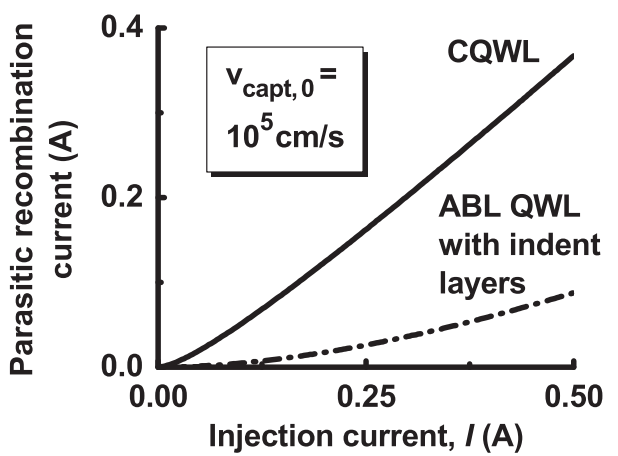

(b)

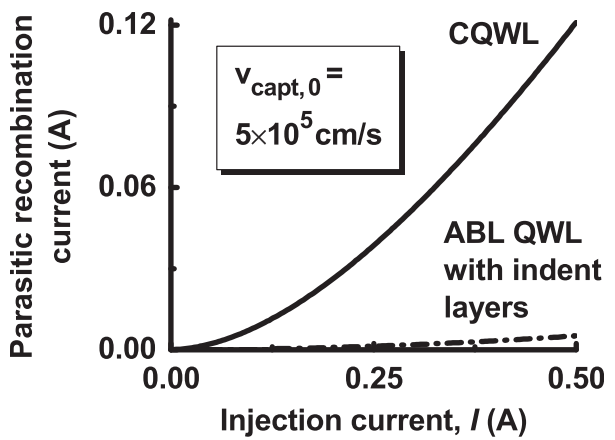

FIG. 7. Parasitic recombination current outside the QW in narrow-ridge short-cavity structures vs. injection current.

Figures 6 and 7 show the current of parasitic recombination outside the $\mathrm{QW}, I^{\mathrm{OCL}}=L W j{ }^{\mathrm{OCL}}$ [see (9) for $j^{\mathrm{OCL}}$ ], against injection current for the high-power and narrow-ridge structures, respectively. As seen from Figs. 6(a) and 7(a), in the case of slow capture, a considerable fraction of the pump current goes into parasitic recombination in both high-power and narrow-ridge CQW structures. While the parasitic recombination current is reduced in the case of moderately slow capture, it still presents a large fraction of the pump current in the narrow-ridge $\mathrm{CQW}$ structure $-I^{\mathrm{OCL}}=0.12 \mathrm{~A}$ at $I=0.5 \mathrm{~A}$ [Fig. 7(b)]. In the ABL QW laser with indent layers, the parasitic recombination current (dash-dotted curves in Figs. 6 and 7) is the current of electron-hole recombination in the indent layers. As seen from Figs. 6 and 7, this current is noticeable only in the case of slow capture in the narrow-ridge structure [Fig. 7(a)].

\section{CONCLUSIONS}

The use of ABLs (one on each side of the QW) has been shown to eliminate the mechanism of sublinearity of the LCC inherently present in the conventional design of QW lasers and associated with (i) noninstantaneous capture of carriers from the OCL into the $\mathrm{QW}$ and (ii) parasitic electron-hole recombination in the OCL. In an ABL QW laser, the parasitic recombination outside the QW is totally suppressed and the LCC is virtually linear no matter how slow is the carrier capture into the QW. In an $\mathrm{ABL} \mathrm{QW}$ laser containing indent layers (parasitic recombination still occurs in these thin layers), even in the case of slow capture of carriers into the $\mathrm{QW}$, the deviation of the LCC from linearity is small. 


\section{ACKNOWLEDGMENTS}

This work was supported by the Ministry of Education and Science of the Russian Federation (Agreement No. 8518).

${ }^{1}$ G. P. Agrawal and N. K. Dutta, Long-Wavelength Semiconductor Lasers (Van Nostrand, New York, 1986).

${ }^{2}$ P. S. Zory, Jr., Quantum Well Lasers (Academic, Boston, 1993).

${ }^{3}$ H. Temkin, D. Coblentz, R. A. Logan, J. M. Vandenberg, R. D. Yadvish, and A. M. Sergent, Appl. Phys. Lett. 63, 2321 (1993).

${ }^{4}$ J. D. Evans, J. G. Simmons, D. A. Thompson, N. Puetz, T. Makino, and G. Chik, IEEE J. Sel. Top. Quantum Electron. 1, 275 (1995).

${ }^{5}$ L. V. Asryan and R. A. Suris, Semicond. Sci. Technol. 11, 554 (1996).

${ }^{6}$ S. Seki, H. Oohashi, H. Sugiura, T. Hirono, and K. Yokoyama, IEEE J. Quantum Electron. 32, 1478 (1996).

${ }^{7}$ L. J. Mawst, A. Bhattacharya, J. Lopez, D. Botez, D. Z. Garbuzov, L. DeMarco, J. C. Connolly, M. Jansen, F. Fang, and R. F. Nabiev, Appl. Phys. Lett. 69, 1532 (1996).

${ }^{8}$ D. Garbuzov, L. Xu, S. R. Forrest, R. Martinelli, and J. C. Connolly, Electron. Lett. 32, 1717 (1996).

${ }^{9}$ R. F. Kazarinov and G. E. Shtengel, J. Lightwave Technol. 15, 2284 (1997).

${ }^{10}$ L. V. Asryan, N. A. Gun'ko, A. S. Polkovnikov, G. G. Zegrya, R. A. Suris, P.-K. Lau, and T. Makino, Semicond. Sci. Technol. 15, 1131 (2000).

${ }^{11}$ L. V. Asryan, S. Luryi, and R. A. Suris, Appl. Phys. Lett. 81, 2154 (2002).
${ }^{12}$ L. V. Asryan, S. Luryi, and R. A. Suris, IEEE J. Quantum Electron. 39, 404 (2003).

${ }^{13}$ L. V. Asryan and S. Luryi, IEEE J. Quantum Electron. 37, 905 (2001).

${ }^{14}$ L. V. Asryan and S. Luryi, "Semiconductor laser with reduced temperature sensitivity," U.S. patent 6,870,178 (22 March 2005).

${ }^{15}$ L. V. Asryan and S. Luryi, Solid-State Electron. 47, 205 (2003).

${ }^{16}$ R. F. Kazarinov and G. L. Belenky, IEEE J. Quantum Electron. 31, 423 (1995).

${ }^{17}$ R. Liang, T. Hosoda, G. Kipshidze, L. Shterengas, and G. Belenky, IEEE Photon. Technol. Lett. 25, 925 (2013).

${ }^{18}$ L. V. Asryan, N. V. Kryzhanovskaya, M. V. Maximov, A. Yu. Egorov, and A. E. Zhukov, Semicond. Sci. Technol. 26, 055025 (2011).

${ }^{19}$ A. E. Zhukov, N. V. Kryzhanovskaya, F. I. Zubov, Y. M. Shernyakov, M. V. Maximov, E. S. Semenova, K. Yvind, and L. V. Asryan, Appl. Phys. Lett. 100, 021107 (2012).

${ }^{20}$ L. A. Coldren and S. W. Corzine, Diode Lasers and Photonic Integrated Circuits (Wiley, New York, 1995).

${ }^{21}$ L. V. Asryan and S. Luryi, Appl. Phys. Lett. 83, 5368 (2003).

${ }^{22}$ D.-S. Han and L. V. Asryan, Nanotechnology 21, 015201 (2010).

${ }^{23}$ I. N. Yassievich, K. Schmalz, and M. Beer, Semicond. Sci. Technol. 9, 1763 (1994)

${ }^{24}$ C. Y. Tsai, Y. H. Lo, R. M. Spencer, and L. F. Eastman, IEEE J. Sel. Top. Quantum Electron. 1, 316 (1995).

${ }^{25}$ S. A. Solov'ev, I. N. Yassievich, and V. M. Chistyakov, Semiconductors 29, 654 (1995).

${ }^{26}$ R. A. Suris, NATO ASI Series E 323, 197 (1996).

${ }^{27}$ A. Dargys and J. Kundrotas, Semicond. Sci. Technol. 13, 1258 (1998). 